\title{
Denuncie agora: uma análise da e-participação no site Urbanias
}

\author{
Rafael Cardoso Sampaio \\ Doutorando em Comunicação e Cultura Contemporâneas \\ (Universidade Federal da Bahia) \\ cardososampaio@yahoo.com.br \\ Maria Paula Almada \\ Mestranda em Comunicação e Cultura Contemporâneas \\ (Universidade Federal da Bahia) \\ mariapaula.almada@yahoo.com.br \\ Nina Santos \\ Mestranda em Comunicação e Cultura Contemporâneas \\ (Universidade Federal da Bahia) \\ ninocasan@gmail.com
}

\begin{abstract}
Resumo Esse artigo propõe uma análise da iniciativa digital civil do Urbanias, um site usado para o envio de denúncias de problemas locais na cidade de São Paulo. Para tanto, montamos um modelo complexo de avaliação de e-participação, que considera a) quem participa; b) como participa; e c) resultados da participação. Com esse objetivo, foram realizadas entrevistas com os gestores, uma avaliação da qualidade técnica do site e uma avaliação qualitativa das denúncias $(n=282)$ e dos comentários realizados. Ao fim, concluímos que o Urbanias tem pouco potencial para engajamento e deliberação, mas pode efetivamente incrementar a transparência e o controle da população em relação ao governo municipal da cidade de São Paulo.
\end{abstract}

Palavras-chave: e-participação, democracia digital, Urbanias.

\section{Introdução}

C uperada a fase de discussão sobre potenciais (positivos ou nega$\checkmark$ tivos) da internet para a democracia, muitos debates e pesquisas têm sido realizados para verificar a qualidade de iniciativas de democracia digital e, principalmente, os fatores capazes de explicar tais resultados (Macintosh; Coleman; Schneeberger, 2009; Sanford; Rose, 2007).

Em especial, há uma considerável gama de estudos sobre projetos de participação política nos ambientes digitais (que trataremos como e-participação) e também diversas pesquisas e relatórios sobre o estado de tais iniciativas em vários países e, especialmente, na Europa (Smith; Macintosh, 2007; Panopoulou et al, 2009). Os resultados são variados. Além de não haver um acordo sobre as principais razões capazes de garantir o sucesso de um programa de e-participação, os resultados dos diferentes projetos variam consideravelmente. Há inúmeros casos bem-sucedidos, assim como diversos outros projetos abandonados por seu relativo ou total fracasso (Meijer; Burger; Ebbers, 2009; DeCindio, Peraboni, 2009).

No caso do Brasil, ao contrário do que é usualmente afirmado, já existe um volume considerável de pesquisas sobre democracia digital 
(ou sobre governo eletrônico com um enfoque democrático) e também sobre e-participação. ${ }^{1}$ Há, todavia, problemas diversos com a pesquisa brasileira, que, a nosso ver, não acompanha as discussões realizadas pela literatura internacional. Há, também, uma concentração de pesquisas a respeito de instâncias mantidas pelo governo e pouca atenção é dada, no geral, a iniciativas civis.

Assim, este artigo propõe a análise de uma iniciativa civil bastante proeminente no país, o Urbanias. Trata-se de um site dedicado à realização de denúncias de problemas diversos na cidade de São Paulo. Os gestores do site enviam as denúncias aos órgãos da prefeitura de São Paulo, que, muitas vezes, respondem diretamente pelo Urbanias, de modo que os gestores funcionam como mediadores entre o cidadão que fez a denúncia e o órgão solicitado. Assim, questiona-se: com sua excessiva ênfase na resolução de problemas locais, é possível pensar em incrementos democráticos através do Urbanias?

Para isso, este artigo foi dividido em quatro seções principais. Primeiramente, realizamos uma revisão da literatura sobre e-participação, que busca tanto apresentar as principais questões e reflexões dessa linha de pesquisa quanto oferecer um modelo complexo para a avaliação de iniciativas de e-participação. $\mathrm{Na}$ segunda seção, debatemos brevemente o conceito de democracia digital from above, apresentando o FixMyStreet ${ }^{2}$ como um modelo de iniciativa bem-sucedida, que é similar ao Urbanias. Na terceira seção, realizamos a avaliação do site, que é basicamente composta por entrevistas com os gestores, uma avaliação da qualidade técnica do site e uma avaliação qualitativa das denúncias $(\mathrm{n}=282)$ e dos comentários realizados. Para finalizar, traçamos algumas considerações acerca do funcionamento do Urbanias, bem como do seu potencial democrático.

\section{Por um modelo de avaliação da e-participação}

Parece-nos que os três principais problemas a respeito da pesquisa sobre participação política on-line no Brasil ${ }^{3}$ são a falta de definições conceituais claras; o fato de diversos estudos trabalharem com premissas não explícitas; e a ausência de ferramentas analíticas adequadas. Em outras palavras, acreditamos que parte considerável dos estudos assuma três suposições: 1) o conceito de e-participação está dado, não sendo necessária muita reflexão para sua definição; 2) a participação (presencial ou digital) é, por si mesma, um valor inestimável da democracia; e 3) não há modelos complexos para a avaliação da participação.

Passemos a esses pontos, iniciando pelo valor da participação. Podemos afirmar, sem muita restrição, que boa parte dos artigos tende a ver a participação como um valor democrático que não pode ser abandonado. Geralmente, esse tipo de perspectiva se relaciona contextualmente com a suposta "crise" das democracias representativas liberais modernas. Os problemas, defeitos ou deficiências apontados seriam diversos, mas, de maneira geral, pode-se afirmar que o principal problema alegado é o gap entre os cidadãos e seus representantes políticos. Isso teria, de maneira geral, diversas consequências democraticamente indesejáveis.

Primeiramente, os representantes teriam autonomia para agir sem prestar contas a seus representados (o que contraria uma das bases da democracia liberal) e, consequentemente, em segundo lugar, as vontades dos indivíduos não estariam bem representadas. $\mathrm{Ou}-$ tras consequências seriam, de um lado, cidadãos apáticos - que não desejariam tomar parte dos processos políticos -, cínicos ou desconfiados (pois passariam a não acreditar que os agentes políticos possam agir beneficamente em seu nome). Por outro lado, os representantes políticos padeceriam de pouca legitimidade, ou seja, suas ações e decisões não seriam legítimas o suficiente perante a sociedade (Bucy, Gregson, 2000; Cohen, 1997; Davis, 2005; Gomes, 2005a, 2005b, 2011; Habermas, 1997; Marques, 2008, 2010). Logo, segundo essa visão,

como a esfera civil resulta ser o âmbito vital da comunidade política democrática, única instância que realmente justifica e legitima a própria democracia, quando a representação dela se afasta, não importando qual seja a razão para tanto, empobrece e definha a democracia e a cidadania. (Gomes, 2011, p. 22)

De maneira geral, essa linha de pesquisa se vale de fontes participacionistas, ${ }^{4}$ e apresenta, em resumo, três grandes justificativas: autonomia dos cidadãos (e.g. Held, 1987), soberania popular (sendo Habermas frequentemente acionado, assim como Rousseau) e a legitimidade política (e.g. Cohen, 1997). Desse modo, tais pesquisas assumem que a participação política não

\footnotetext{
1. Vide levantamento em: http://www.comunicacaoepolitica.com.br/blog/2011/07/democracia-digital-no-brasil-uma-prospeccao-da-literaturaexistente/.

2. http://www.fixmystreet.com/.

3. Gomes (2011) afirma que não é algo específico do Brasil, mas da literatura. Nosso ponto é apenas concentrar a questão nas pesquisas brasileiras.
}

4. Desde clássicos como Rousseau e Stuart Mill a autores da Nova Esquerda, como Pateman (1992) e Macpherson (1978). 
apenas é desejável, como é vital para a democracia, constituindo, assim, um valor por si só.

Como defendido por Gomes (2011), a participação não pode sequer ser considerada democrática se não objetivar uma melhoria para a comunidade política, caso contrário, mesmo a participação em grupos de ódio, racistas ou xenofóbicos seria democraticamente válida. De forma complementar, pouca valia tem uma participação que não incremente nenhum valor democrático ou que seja direcionada para um público inadequado. Logo, uma definição é necessária.

De maneira ampla, a "participação política é tipicamente definida como envolvimento direto dos cidadãos em (ou influência sobre) processos governamentais" (Bucy, Gregson, 2000, p. 359, tradução nossa). Significaria "se juntar", "tomar parte", tanto no sentido de fazer parte de alguma atividade ou discussão na comunidade como no sentido de assumir algum papel nas tomadas de decisão (Sæbø et al, 2008). Ou de forma um pouco mais desenvolvida, pode-se entender participação política como o envolvimento dos indivíduos na "proposição de agenda pública, processos decisórios e formação de atividades políticas diversas das organizações e instituições responsáveis pelo desenvolvimento de políticas" (Frewer; Rowe, 2005, p. 5, tradução nossa).

De forma complementar ao dito no início desta seção, os governos, de maneira geral, procurariam promover a participação para incrementar a eficácia, a aceitação e a legitimidade de processos políticos, ao passo que cidadãos, organizações não governamentais, lobistas e grupos de pressão podem demandar a participação para promover seus próprios interesses, seja através do sistema político estabelecido, seja através de ativismo ou do processo de formação de opinião (Sæbø et al, 2008, p. 401).

Por sua vez, na avaliação da literatura de e-participação, Sæbø e equipe (2008) concluem que, de maneira geral, o $e$ (electronic) se refere ao uso de novas tecnologias de informação e comunicação (particularmente a internet) para processos de participação e de consulta. Geralmente afirmam que a tecnologia tem de alterar ou mesmo transformar o envolvimento do cidadão em processos deliberativos ou em tomadas de decisão. Seriam, principalmente, entendidos como uma interação mediada por tecnologias entre a esfera da sociedade civil e as esferas política e administrativa (2008, p. 402).

Um dos problemas de tais definições amplas ou mesmo vagas é o fato de que diferentes áreas de estu- dos ou objetos podem acabar sendo incluídas sob essas definições. Muitas vezes tais processos têm pouca ou nenhuma participação no sentido democrático estrito (Grönlund, 2009).

\section{Definindo e-participação}

Assim, as definições de e-participação ainda carecem de melhor explicitação dos três pontos principais de um processo participativo: 1) quem participa; 2) como participa; e 3) quais os resultados da participação. A partir desses três pontos, pretendemos criar um modelo de avaliação.

No primeiro quesito, não nos parece haver dúvida de que, se estamos tratando de uma participação benéfica à democracia, é a esfera civil quem participa. É necessário, no entanto, observar quatro pontos que merecem discussão. Primeiramente, como Gomes (2011) alerta, muitas vezes a esfera civil é confundida com organizações cívicas, ou seja, a participação se limita apenas aos grupos coletivos da sociedade civil denominada organizada. Há diversos motivos para se dar voz e participação a tais coletivos, ${ }^{5}$ mas vale o alerta de Gomes. Diversos programas participativos (especialmente com pensamentos excessivamente de esquerda) ignoram (conscientemente ou não) o cidadão atomizado, não organizado e geralmente não ativo em relação ao sistema político, mas é importante ressaltar que estes cidadãos representam a maior parte da população.

Ainda no quesito de quem participa, não se pode ignorar a questão de um público-alvo (Macintosh; Whyte, 2008). Certas políticas públicas ou mesmo iniciativas de participação são pensadas tendo certos grupos em mente, como as políticas para minorias. Em alguns casos, o público-alvo pode ser baseado em regiões de uma cidade, por exemplo.

Outro ponto é que, ao se trabalhar com tecnologias digitais, deve-se considerar a forma de seleção dos participantes. Potencialmente todos os cidadãos podem participar, ${ }^{6}$ mas, ao contrário do pensamento de que "quanto mais participação melhor", 7 certos formatos de participação podem exigir um público menor. Nessa linha, Cohen e Fung (2004) afirmam que participação e deliberação, geralmente tomadas como indissociáveis, são inversamente proporcionais. Ou ainda, quanto mais participantes, pior tende a ser a deliberação nos seus altos quesitos. Logo, uma boa

\section{Vide Maia (2007) para alguns deles.}

6. Obviamente, acessos e habilidades de usar a internet não podem ser desconsiderados. Wilhelm (2001), por exemplo, afirma que, se não bem pensadas, iniciativas digitais podem reforçar diferenças socioeconômicas, uma vez que grupos minoritários, usualmente não contemplados em políticas públicas, também não têm acesso e habilidade para participar efetivamente, podendo ser excluídos novamente.

7. Bobbio (1997) nos lembra que um governo com excessiva democracia (ou participação, no caso) também poderia ter suas funções básicas emperradas 
deliberação pode exigir poucos participantes. Além disso, se, por um lado, um programa on-line permite potencialmente a participação de toda a população, por outro lado, questões técnicas podem inviabilizar sua realização. Se um número muito grande de usuários participar ao mesmo tempo, o servidor do website pode simplesmente cair (uma ocorrência usual). Ainda nesse sentido, podem-se tomar cuidados para evitar grupos muito homogêneos, pouco representativos (Meijer;Burger; Ebbers, 2009) ou com poucas habilidades para utilizar a internet (Davis, 2005; Wilhelm, 2001).

Finalmente, uma consequência do ponto levantado acima e o último da questão de quem participa é "quantos participam". Em um programa participativo presencial, como um orçamento participativo ou um conselho de política pública, é considerável que apenas $1 \%$ dos eleitores participe e que tal número seja considerado razoável (Avritzer, 2005). Porém, qual o número desejável quando tratamos de um projeto de e-participação no qual, potencialmente, todos podem ser envolvidos? Por exemplo, o PPA participativo do Rio Grande do Sul ${ }^{8}$ envolveu $15 \%$ de sua população ativa no processo decisório, sendo que $10 \%$ do total de votos foram on-line. Cabe, então, questionar quão significativo seria tal número.

Gomes (2011) apresenta uma saída interessante. Em sua avaliação, não se trata de todos estarem sempre participando, de termos altos números de cidadãos em todos os exercícios participativos. Mais importante que isso seria ter um maior número de instâncias ou canais de participação, que permanecessem abertos. Ou seja, ao invés de considerar que o cidadão desejável em uma democracia participativa seja aquele que participa ao máximo, em todas as oportunidades de que dispõe, sugere Gomes que se deve trabalhar com os participantes reais disponíveis, mesmo que não desejem participar sempre ou em todas as questões. Dessa forma, se houver canais abertos, quando estes desejarem participar, a possibilidade será bem-vinda. ${ }^{9}$

Essa visão, todavia, não inviabiliza a possibilidade de se pensar em números desejáveis para um exercício de e-participação. O mais simples é assumir que este número não é absoluto. Diversos processos participativos têm um público-alvo e, por conseguinte, terão um número desejável de participantes. Certos processos (muito específicos e direcionados, por exemplo) podem ter um número de participantes pequeno (em relação à população geral), mas ser um sucesso, e o inverso também pode ser verdadeiro. Assim, a comparação é um padrão válido. Se um número ideal é utópico, difícil de ser definido e, talvez, indesejável, a melhor solução é avaliar programas participativos similares e seu número de participantes (em relação à população geral).$^{10}$

O segundo ponto a ser avaliado é o "como participam", ou o desenho do projeto (Macintosh, Whyte, 2008). Tratando-se de um programa participativo on-line, duas questões principais devem ser avaliadas. Primeiramente, o formato da participação. Assim, como diversos autores pensam no desenho institucional de instituições participativas (Fung, 2004), questões similares devem ser avaliadas em programas participativos on-line (Marques, 2010; Sampaio, 2011). ${ }^{11}$

A avaliação de iniciativas de e-participação realizada pelo Conselho Europeu (Smith, Macintosh, 2007) apresenta definições básicas de um projeto: a) quem iniciou o projeto (tipo do ator: líder político, civil, partido, $\mathrm{ONG}$, cidadão, mídia ou organização comercial)?; b) quando foi iniciado?; c) qual o principal objetivo/meta da iniciativa?; d) como foi desenvolvido a partir da ideia inicial e quais foram os prazos limite (timelines)?; e) quando e como terminou (se terminou)?; f) como a iniciativa se relaciona a outras iniciativas democráticas na área (tanto on-line quanto off-line)? Tal base pode ser complementada pelos critérios do relatório da WEP.Dep (Smith, Macintosh, 2007), que ainda estabelecem: g) área de participação, onde a categoria de ferramenta é relevante (exemplo: provisão de informação, formação de comunidade/ ambientes colaborativos, consulta, campanha, eleições, deliberação, discurso, mediação, planejamento espacial, pesquisas de opinião e votação); h) direção da comunicação (nível de empowerment); e i) moderação ou facilitação para a instância participativa (agentes treinados para moderar e fomentar as discussões e a participação).

Finalmente, ainda no desenho da e-participação, deve-se considerar se ela será exclusivamente on-line ou se contará com momentos presenciais. É claro que diversas vantagens de um programa exclusivamente on-line podem ser perdidas, mas algumas avaliações

\footnotetext{
8. http://www.participa.rs.gov.br/.

9. É importante ressaltar que tal linha defende o valor da abertura dos processos participativos a todos os interessados, enquanto nosso trabalho lida com a possibilidade de processos participativos mais restritos. Essa discussão se encontra na questão da democracia vs. eficiência. Ou, ainda, quanto mais eficiente for um método de participação, menos democrático ele tende a ser e vice-versa. Nosso modelo enfatiza fortemente a questão da geração de efeitos democráticos, mas não ignora alguns pontos da eficiência, buscando um equilíbrio entre os pontos.

10. Evidentemente, há ressalvas, como a cultura participativa de um país ou de uma região específica ou o número de acessos à internet no local, ou ainda o tamanho absoluto da população (será mais fácil alcançar uma maior proporção da população em ambientes menores).

11. Marques (2010) frisa que se, por um lado, a e-participação pode ser considerada mais fácil e ter um menor custo para o cidadão, por outro lado, parte desse custo é transferido para seu promotor. Ou seja, novas tarefas serão adicionadas ao gestor público, quando este promover instâncias participativas, como tratar e responder às mensagens enviadas on-line, por exemplo. O que, geralmente, significa um aumento dos custos do processo político, como o aumento de funcionários.
} 
têm indicado que o amálgama das duas técnicas (ou, ainda, parte do processo on-line e parte presencial) pode tornar o processo mais bem-sucedido ${ }^{12}$ (DeCindio, Peraboni, 2009; Åström, Grönlund, 2012).

O segundo quesito do processo é o design ou desenho das ferramentas. Primeiramente, não se pode ignorar que o design das ferramentas é uma consequência das forças políticas que estão por trás de seu desenvolvimento (Chadwick, 2006; Ferber et al, 2005; Gomes, 2007; Marques, 2010; Salter, 2004). Estudos demonstraram que, por exemplo, um site atrativo pode ser significativo para que os usuários retornem a ele (Coleman et al, 2008). De modo similar, ferramentas mal desenhadas podem atrapalhar a discussão entre os cidadãos (Janssen, Kies, 2005), a participação em sites de governo (Bezerra, Jorge, 2011; Marques, 2008) ou em programas desenhados para serem participativos (Marques, 2010; Sampaio, 2011). Nesses casos, o design é parte significativa da ação política (Wright, Street, 2007). ${ }^{13}$

Por outro lado, não se pode cair no determinismo tecnológico (Sampaio, 2010). Muitas pesquisas de e-participação focam excessivamente o design das ferramentas digitais, ignorando que elas também são moldadas por seus usuários e pelas diferentes forças políticas envolvidas no processo participativo (Macintosh, Coleman e Schneeberger, 2009; Meijer;Burger; Ebbers, 2009). Lee Salter (2004) nos lembra que a forma como as ferramentas são utilizadas também importa e que tal uso pode inclusive se distinguir do objetivo inicial da ferramenta, moldando o seu desenvolvimento posterior.

Por fim, os "resultados da participação". Usualmente, a questão dos resultados é tratada sob a perspectiva do empoderamento (empowerment). O poder de decisão precisa, em alguma medida, estar nas mãos dos participantes. Arnstein (1971) é uma das principais expositoras de tal visão. Para a autora, a participação está diretamente ligada ao poder. E nos seus níveis mais baixos, ela só tem a ver com terapia ou mesmo enganação da população, pois a participação real só acontece com poder efetivo. Em outras instituições participativas, como o orçamento participativo, o empoderamento é igualmente visto como necessário (Fung, 2004). Por sua vez, nas avaliações de e-participação, a questão do poder é fortemente valorizada, estando no degrau mais elevado das tipologias participativas (e.g. Panopoulou et al, 2009; vide também a crítica de Grönlund, 2009).
Nesse sentido, a questão da influência é vital para os projetos de e-democracia. Marques (2010) afirma que o fato de os participantes serem incentivados para tais experiências participativas e saberem que suas contribuições serão consideradas ou terão efetivo poder de decisão é grande parte da motivação. Ou, em outras palavras, os arranjos participativos precisam ser oportunidades atraentes, ou seja, "conjunção de ocasiões e circunstâncias em que meios podem produzir fins desejáveis de maneira que os custos (a energia despendida, por exemplo) sejam largamente recompensados pelos benefícios (recompensas decorrentes de se alcançar a finalidade da ação)" (Gomes, 2011, p. 37).

Contudo, a influência ainda pode ser verificada em outras questões. Aqui, dois pontos merecem destaque. Primeiramente, não apenas em tomadas de decisões, mas em questões das agendas (agenda-setting) de discussões. Um perigo de associar influência ao empoderamento é conectar diretamente a participação ao momento final da política pública. Se a participação pode acontecer em diferentes momentos da proposição da política, é importante que a cidadania também seja capaz de influenciar as agendas de discussão e de proposições dos governos (Åström, Grönlund, 2012; Coleman, Blumler, 2009; Meijer; Burger; Ebbers, 2009). Finalmente, na questão da influência, existe uma consideração vital. Para Wilson Gomes (2011), a participação política só é democraticamente relevante se aumentar a capacidade concorrencial do cidadão individual. Para Gomes, o sistema de tomada de decisão política é influenciado por inúmeros atores políticos, como os partidos, as organizações da sociedade civil, os cidadãos individuais e os próprios representantes políticos (e suas ligações partidárias). São inúmeros interesses concorrentes entre si. Ainda segundo o autor, não se trata de pouca participação política do cidadão necessariamente, mas de pouca capacidade concorrencial do cidadão individual para afetar as decisões políticas, a agenda de discussão ou, no mínimo, ter mais controle sobre seus representantes. A capacidade concorrencial desse cidadão não organizado seria aumentada por diversas ações, como melhores informações, transparência e participação política.

Porém, a visão de Gomes (2011) aponta para o caminho de não pensarmos necessariamente em participação civil massiva, mas em mais meios e oportunidades qualificadas de o cidadão concorrer com maior influência com os diferentes atores sociais. Sua defesa está em não se exigir apenas participação, mas

12. No caso do Brasil, o orçamento participativo fez o inverso. Adicionou uma etapa digital a seu processo participativo, o que aumentou consideravelmente o número de participantes (Sampaio, 2011). Apesar de não se tratar do mesmo caso, é outra evidência de que processos amalgamados podem apresentar melhores resultados.

13. Há casos em que as ferramentas digitais são desenhadas por profissionais de informática com pouca noção de valores políticos ou democráticos, o que pode ter consequências negativas (Ferber et al, 2005; Marques, 2010). 
empoderamento civil, que é alcançado de inúmeras maneiras (conclusão muito presente nos estudos de e-participação, conforme Sæbø et al, 2008).

Nesse sentido, já que desejamos nos ater à participação política, acreditamos que haja outra saída. Se a participação política não pode ser considerada um fim democrático em si mesmo, é plausivel, por outro lado, esperar que ela crie, incremente ou transforme valores democráticos. Logo instituições ou arranjos participativos devem promover bens democráticos. ${ }^{14}$ Segundo Macintosh e Whyte (2008, p. 24), os principais valores democráticos a serem incrementados pela e-participação são: representação, engajamento, transparência, deliberação, igualdade (com toques de pluralidade) e controle da comunidade. A esses podem ser acrescentados ou subtraídos outros valores democráticos de acordo com as necessidades do público participante ou mesmo do órgão que propõe o projeto participativo. Como Grönlund (2009) critica, democracia não é tecnologia. A e-participação não pode ser avaliada exclusivamente por sua eficiência técnica, mas, principalmente, por sua capacidade de incrementar a democracia.

Entretanto, a ideia de tarefa de Coleman e Blumler (2009) não pode ser ignorada. Nenhum projeto de participação ou de democracia (digitais ou presenciais) será plenamente capaz de fazer avançar todos os bens democráticos. Deve-se pensar na complexidade das sociedades democráticas e dos governos. Diferentes arranjos participativos podem incrementar diferentes valores democráticos e se pode pensar na complementaridade entre eles (Smith, 2009).

Logo, nosso modelo: I) Quem: a) esfera civil organizada e não organizada (Gomes, 2011); b) público-alvo (Macintosh, Whyte, 2008); c) seleção dos participantes (Fung, 2004); d) número desejável de participantes por comparação. II ) Como: e) formato da participação (Smith, Macintosh, 2007), por sua vez dividido por: 1) quem iniciou o projeto?; 2) quando foi iniciado?; 3) qual o principal objetivo/meta da iniciativa?; 4) como foi desenvolvida a ideia inicial e foram definidos os prazos (timelines)?; 5) quando e como terminou (se terminou)?; 6) como a iniciativa se relaciona a outras iniciativas democráticas na área (tanto on-line quanto off-line)? 7) área de participação, no qual a categoria de ferramenta é relevante; 8) direção da comunicação (nível de empowerment); e 9) moderação ou facilitação para a instância participativa (agentes treinados para moderar e fomentar as discussões e a participação) e f) design das ferramen- tas digitais (vários). III) Resultados: g) bem democrático a ser incrementado (Macintosh, Whyte, 2008): 1) representação; 2) engajamento; 3) transparência; 4) deliberação; 5) igualdade; 6) pluralidade; 7) controle cognitivo. ${ }^{15}$

\section{Democracia digital de baixo}

Em nosso modelo acima apresentado, existe o item "direção da participação". Para a avaliação da Wep.Dep, isso está relacionado ao nível de empowerment, que é utilizado em uma escala. Para outros autores, isso está mais relacionado a quem promove e controla o instrumento participativo. Há toda uma linha de pesquisa que defende a importância de que seja o próprio Estado a ofertar e gerir oportunidades de e-participação. Esta linha (e-governo, e-governança e parte dos estudiosos chama de e-participação e e-democracia) defende tal escolha por todos os motivos levantados no início do texto: separação entre a esfera política formal e a civil, falta de legitimidade dos políticos e de interesse pelos cidadãos. Dessa forma, é natural e desejável que o próprio Estado abra suas portas para a participação popular, o que pode incrementar diversos processos democráticos, como accountability, transparência, deliberação, participação ou mesmo de gestão, como eficácia (ver Chadwick, 2006 e Marques, 2008 para uma ampla discussão do tema).

Por outro lado, uma segunda linha defende a democracy from above ou bottom up, ou seja, criada e mantida por iniciativa civil. ${ }^{16}$ Segundo Macintosh, Coleman e Schneeberger (2009), as instituições governamentais estão na primeira linha no desenvolvimento de projetos de e-participação. Isso leva à consequente desvalorização da importância de participação espontânea na rede, guiada por cidadãos, por organizações voluntárias ou por grupos de pressão (p. 5). Dessa forma, muita atenção estaria sendo dada às aplicações que se encontram no local que têm a menor chance de gerar uma mudança significativa: o reino da política convencional. Organizações, instituições, partidos, governos e campanhas tendem a adaptar as novas tecnologias para suas missões e agendas existentes (Coleman, Blumler, 2009). Ou, ainda, os responsáveis por introduzir novas formas de participação cidadã na tomada de decisão política podem

14. Segundo Smith (2009), os principais bens democráticos são: inclusão, controle popular, julgamento considerado, transparência, eficiência e capacidade de ser transferido para outras realidades.

15. Substituímos a ideia original de "controle da comunidade". Em nossa visão, tal defesa dos autores é excessivamente comunitarista. A ideia de controle cognitivo significa que o cidadão está acompanhando e monitorando as ações de seus representantes e poderá utilizar tal conhecimento para mantê-los accountable, tanto através das eleições como de outras formas de constrangimento (como a mídia ou órgãos públicos de accountability).

16. Aqui, no geral, a literatura pouco enfatiza se é melhor que seja de indivíduos não associados ou de grupos cívicos. 
ser aqueles que explícita ou implicitamente se opõem a elas (Kolsaker, Lee-Kelley, 2008). ${ }^{17}$

Coleman (2009), um dos grandes defensores de tal análise, afirma que apenas em tais plataformas espontâneas e cidadãs podem nascer projetos que ofertem múltiplas fontes de informação, que possam produzir uma visibilidade não controlada pelas instituições do Estado e capazes de gerar transformações reais na política.

Nesse sentido, acreditamos que haja uma miríade de boas iniciativas digitais iniciadas ou mantidas pela esfera civil. ${ }^{18} \mathrm{Um}$ dos exemplos mais proeminentes é o do FixMyStreet (FMS) (algo como "Conserte minha rua”) britânico. Basicamente, é um programa iniciado pela My Society ${ }^{19}$ em 2007. Um site no qual os cidadãos podem apresentar os problemas de pequeno porte da sua região e os encarregados pelo site os enviam para o órgão responsável da municipalidade. Através do FMS, os usuários podem acompanhar suas demandas e cabe a eles relatarem se o problema foi resolvido ou não. Por sua própria estrutura, o FMS permite não apenas relatar os problemas e propiciar conhecimento de outros problemas relatados, mas tem grande potencial para a formação de comunidade on-line, uma vez que ele funciona em uma forma similar a um fórum on-line (Bayakurt, 2011).

Para Meijer, Burger e Ebbers (2009) o FMS seria um exemplo de iniciativa na qual "cidadãos pressionam o governo para implementar políticas públicas com maior precisão" (p. 106, tradução nossa). Em classificação similar, Dörk e Monteyne (2011) consideram que são relatórios ou requisição de erros (bugs) a serem consertados. Na visão dos autores, a grande vantagem desses projetos seria o fato de tornarem os problemas públicos, uma vez que sistemas similares do governo recebem o insumo cidadão, mas não o tornam público. "O FixMyStreet aumenta a voz do cidadão ao voltar os olhos do público para problemas pendentes" (p. 3, tradução nossa).

Assim, em alguma medida, programas como o FMS poderiam acarretar inúmeras vantagens democráticas, como um público mais informado da situação de sua comunidade (ou cidade) e mais confiante em participar, tornando-se coprodutor da gestão municipal. Além disso, tornariam o poder público mais accountable, uma vez que passa a estar mais sob o controle de uma iniciativa civil, gerando maior transparência na resolução de problemas públicos (Bayakurt,
2011; Dörk, Monteyne, 2011; King, Brown, 2007; Meijer, Burger e Ebbers, 2009).

Segundo o website (FMS, 2011), foram 170 mil atualizações nos relatos (respostas dos órgãos públicos), mil relatos apenas na última semana e mais de 2 mil consertos no último mês. ${ }^{20} \mathrm{O}$ valor do FMS chegou a ser reconhecido pelo parlamento britânico, que aprovou fundos para a criação do projeto (King, Brown, 2007), uma vez que ele seguia as lógicas da política de e-democracia do Reino Unido (2007).

Por outro lado, King e Brown (2007) realizaram uma vasta análise no site, o que incluiu a avaliação de postagens e entrevistas com os gestores do site e com comunidades locais. Apesar das inúmeras vantagens apresentadas pelo projeto, eles concluem que o FMS duplica projetos já existentes nos websites do governo britânico; apresenta pouca visibilidade, sendo pouco utilizado pelas comunidades; e como são os usuários a darem a atualização final, os relatos tendem a ficar desatualizados. Além disso, se, em teoria, o FMS teria grande potencial para o diálogo e a formação de comunidade, a análise demonstrou que não há evidências empíricas desses resultados. Os indivíduos utilizam o site apenas para reportar os problemas e não há muita discussão advinda disso. Finalmente, os autores concluem que o site deveria investir em uma moderação mais ativa e incentivadora e tentar incluir os líderes locais no website para facilitar a formação de comunidades on-line.

Por sua vez, Baykurt (2011) levanta uma série de problemas do FMS. Em resumo, o autor afirma que: 1) faltam incentivos aos participantes ativos (ele sugere prêmios ou medalhas virtuais aos mais comprometidos); 2) falta informação qualificada no site sobre o funcionamento do website e de outras formas de o cidadão enviar suas demandas ao poder público; 3) o FMS ainda incentiva uma ação passiva dos cidadãos, que apenas informam os problemas, enquanto o poder público os resolve (em uma espécie de clientelismo); 4) o FMS só permite insumo relacionado a problemas e questões negativas, não abrindo espaço para sugestões e proposições positivas dos participantes; e 5) o FMS incentiva o foco em questões extremamente pequenas, locais e efêmeras, impedindo discussões sobre problemas mais estruturais. Tais avaliações e críticas serão consideradas em nossa análise do Urbanias.

17. É um dos três grandes empecilhos levantados por Marques (2010) para a criação e a implementação de projetos de participação política on-line.

18. Vide a prospecção de Meijer e equipe (2009) para projetos europeus, e Rossetto e Carreiro (2012) e Rossetto, Carreiro e Almada (2011), para iniciativas brasileiras.

19. http://www.mysociety.org/. Associação voluntária britânica, que cria e administra inúmeros programas de democracia digital no Reino Unido, como o FixMyStreet e o They Work for You.

20. Dados de dezembro de 2011. 


\section{O Urbanias}

Apesar de existir uma versão brasileira do FixMyStreet, ${ }^{21}$ optamos pela análise de um programa similar, mas que é mais antigo e mais bem estabelecido. Trata-se do Urbanias. ${ }^{22} \mathrm{O}$ site foi criado em 2009 e busca permitir que seus usuários façam reclamações e pedidos diversos em relação à cidade de São Paulo. Como no FMS original, geralmente são realizadas denúncias de problemas existentes na cidade, que são encaminhadas pelo site para o órgão responsável e o cidadão acompanha pelo site a resposta do município. $\mathrm{O}$ site, que tem um patrocínio da Financiadora de Estudos e Projetos (Finep), ${ }^{23}$ é composto essencialmente por jornalistas, mas é gerido por uma empresa (Rossetto e Carreiro, 2012; Balago, 2011).

A ideia, segundo seu criador, é tornar mais fácil o consumo de informações relevantes à vida nos bairros, baixando o custo de transação para as pessoas participarem e se mobilizarem. Seria, assim, uma tentativa de mesclar conhecimento/vivência local com ferramentas digitais para aumentar a transparência na relação do cidadão com o Estado e, potencialmente, induzir a melhoria da gestão pública municipal $(\mathrm{Mu}-$ nhoz, 2010; Urbanias, 2011).

Dessa maneira, de forma similar ao FMS, o site é organizado na forma de fóruns on-line, que são divididos por categorias (transporte, barulho, lixo, acessibilidade, segurança etc.), tendo como foco "questões que concernem à qualidade de vida na cidade e, por consequência, afetam o dia a dia dos moradores" (Rossetto; Carreiro e Almada, 2011, p. 9).

Ao realizar uma denúncia, o usuário deve necessariamente localizá-la espacialmente. Há um mapa que faz o georreferenciamento de todas as denúncias do site utilizando a tecnologia do Google Maps. Além disso, a denúncia deve necessariamente entrar em uma categoria do site, conter um assunto e o nome de seu autor (que deve estar cadastrado no site). Ao selecionar cada denúncia marcada no mapa, o usuário terá acesso “à denúncia completa, à posição do Urbanias (se já encaminhou o assunto a algum órgão), à posição do órgão responsável (se este já tiver emitido alguma resposta) e aos comentários dos outros cidadãos, que podem também apoiar quem fez a denúncia” (Rossetto; Carreiro e Almada, 2011, p. 10).

Uma primeira análise do Urbanias já foi realizada por Rossetto e equipe (2011). Eles avaliam que o site é motivador para a participação, pois oferece presença em redes sociais, a maior parte das denúncias recebe uma resposta do órgão oficial e há informações atualizadas sobre os problemas da cidade através das denúncias ou do blog, além da proximidade dos relatos ao cotidiano dos usuários. Segundo a análise, mais de $70 \%$ das denúncias avaliadas receberam uma resposta, embora os autores tenham optado por uma amostra pequena, de menos de 30 relatos. Assim, o site constituiria uma plataforma de informação sobre questões concernentes à política e seriam canais de participação efetiva, uma vez que boa parte das denúncias é considerada pelos órgãos públicos. Por outro lado, os autores detectaram a falta de participação de membros da esfera política decisória e uma pequena quantidade de usuários cadastrados.

\section{Metodologia}

Basicamente, o estudo proposto foi realizado de duas formas. Primeiramente, como demonstrado acima, foi criado um modelo para a análise da instância participativa (apresentado acima). Em segundo lugar, optamos por avaliar fontes que estivessem ligadas ao website e também aos seus usuários. Assim, foi realizada uma entrevista com um dos responsáveis pelo site (Balago, 2011) e utilizada a entrevista com Ricardo Joseph realizada por Munhoz (2010). Depois, para averiguarmos as possibilidades de participação cidadã, avaliamos a qualidade do design do website e realizamos uma análise substancial de denúncias disponíveis no website. Segundo Balago (2011), foram 1022 denúncias realizadas até novembro de 2011, porém este total não está visível através dos mapas disponíveis nas nove categorias do site. Analisamos, então, as 282 que foram localizadas através dos mapas disponíveis nas categorias. Essa análise permite, principalmente, nos indicar como os usuários participam e qual o bem democrático (caso haja algum) incrementado ao final do processo.

\section{Resultados}

\section{I) Quem}

A) Esfera civil organizada e não organizada: não há nenhuma definição clara a tal respeito. Aparentemente, tanto a sociedade civil "organizada" quanto o cidadão individual são capazes de participar do Urbanias. Todavia não há, em nossa avaliação das denúncias, sinais claros de organizações ou grupos cívicos, denotando que os cidadãos individuais participam mais diretamente. 
B) Público-alvo: não parece haver algum, uma vez que o site é aberto a todos, mas só se propõe a se manifestar e encaminhar denúncias exclusivamente sobre a cidade de São Paulo.

C) Seleção dos participantes: é aberta a todos os interessados. A única restrição é a necessidade de se cadastrar previamente. A exigência de localização da denúncia induz a presença apenas de usuários que efetivamente conheçam a cidade. Nas entrevistas e no website, não foi possível conseguir um perfil mais específico dos usuários, como dados demográficos e afins.

D) Número desejável de participantes por comparação: o FixMyStreet não divulga seu número de usuários, mas apenas de reports (relatos ou denúncias) e de casos resolvidos. Já o Urbanias tem 1180 usuários (Balego, 2011). Por outro lado, o FMS apresenta cerca de 170 mil denúncias que já receberam respostas de 2007 a 2011 (FMS, 2011), enquanto o Urbanias, como já dito, teve apenas 1022. Há, claro, algumas explicações para isso, como o fato de o FMS abarcar todo o Reino Unido, que dispõe de maior acesso à internet que o Brasil, e o fato de ter esse projeto dois anos a mais. De toda forma, em números absolutos e considerando a população de São Paulo, os números do Urbanias ainda são modestos.

\section{II ) Como}

\section{E) Formato da participação}

e.1) Quem iniciou o projeto: segundo Balego (2011), inicialmente a ideia foi desenvolvida por Ricardo Joseph e colaboradores individuais. Posteriormente, foi criada uma empresa para gerir o Urbanias, que não tem qualquer ligação com ONGs, com partidos políticos ou diretamente com o governo.

\section{e.2) Quando foi iniciado? Em 2009.}

e.3) Qual o principal objetivo/meta da iniciativa? Segundo seu criador, o objetivo principal do site é ser um mediador direto com o poder público. Como consequência, o site ofereceria uma plataforma simples e fácil para o cidadão se informar, denunciar e participar da vida de sua comunidade (Balego, 2011; Munhoz, 2011).

e.4) Como foi desenvolvida a ideia inicial e quais foram os prazos? Como uma iniciativa espontânea, o Urbanias não foi criado com o estabelecimento de prazos. Segundo seu criador, Ricardo Joseph ( $\mathrm{Mu}-$ nhoz, 2010), ele se inspirou em sua experiência pessoal nos EUA e em diferentes formas de engajamento e envolvimento da população local com problemas da comunidade. $\mathrm{O}$ objetivo inicial era justamente criar uma plataforma on-line que facilitasse e incentivasse esse envolvimento cidadão em questões cotidianas.

e.5) Quando e como terminou (se terminou)? De maneira similar, o projeto não foi pensado de maneira fechada, logo não tem um prazo final. Após esses anos de experiência, os seus gestores estão avaliando diferentes formas de expansão e melhoria. O seu criador admite que o número de usuários e denúncias ainda é baixo. Uma ideia, para superar esse problema, é a criação de aplicativos para smartphones (Munhoz, 2010).

e.6) Como a iniciativa se relaciona a outras iniciativas democráticas na área (tanto on-line quanto off-line)? Segundo Balego (2011), Joseph achou que as diferentes iniciativas norte-americanas de engajamento da população local eram relevantes, mas não afirma que o Urbanias foi baseado em algum projeto democrático específico, como o FMS. Segundo Joseph, eles entraram na rede \#webcidadania, que é uma espécie de parceria entre as diferentes iniciativas, de democracia digital e e-participação da esfera civil e estão avaliando a maneira de melhor imbricar os diferentes projetos entre si.

F) Área de participação, onde a categoria de ferramenta é relevante: entre as opções do relatório da WEP.Dep (Smith e Macintosh, 2007), certamente a principal função do Urbanias é a mediação, mas seu foco é a gestão municipal. O baixo número de comentários e de diálogos encontrados (vide a análise a seguir) demonstra que o site tem pouco potencial deliberativo, mesmo para formação de comunidades on-line.

G) Direção da Comunicação: como já afirmado, é um programa bottom-up. Como tal, ele é espontâneo e independente (Coleman, 2009), o que resulta em maior liberdade e em menor hierarquia no momento da participação cidadã, mas, em contrapartida, seu empowerment é menor. Como a seguir serão analisadas, boa parte das denúncias é verificada pela municipalidade, mas não há metas ou garantias de verificação ou de resolução dos problemas apontados pelos cidadãos.

H) Moderação ou facilitação para a instância participativa (agentes treinados para moderar e fomentar as discussões e a participação): de acordo com nossa análise, as denúncias não são moderadas. Encontramos inclusive denúncias falsas, brincadeiras ou mesmo questões nada pertinentes (como ofensas). Nossa análise também não mostrou a ação do 
Urbanias no sentido de facilitar ou incentivar a participação e a discussão entre os integrantes do site. Por outro lado, pode-se argumentar que o fato de o Urbanias postar os encaminhamentos e os resultados das denúncias poderia funcionar como um incentivo, todavia não se trata do mesmo incentivo defendido por autores da e-participação. ${ }^{24}$

I) Design das ferramentas digitais: para analisar o design da ferramenta utilizamos alguns critérios desenvolvidos por Karini (2011). Em seu trabalho, são desenvolvidas categorias de análise de websites governamentais, que, apesar de terem um objeto diferente, guardam algumas semelhanças com o site aqui analisado. Assim, optamos por fazer uma seleção das categorias importantes para a análise aqui proposta, avaliando cada quesito em cinco níveis: 1 - péssimo, 2 - regular, 3 - mediano, 4 - bom, 5 - ótimo.

Tabela 1 - Avaliação do design do Urbanias

\begin{tabular}{|l|l|}
\hline Usabilidade & Avaliação \\
\hline Mecanismos de busca & Inexistem \\
\hline Mapa do site & $\begin{array}{l}\text { Existe na barra inferior do site, } \\
\text { mas de maneira simples. }\end{array}$ \\
\hline $\begin{array}{l}\text { Reconhecimento e } \\
\text { orientação do sistema }\end{array}$ & 3 \\
\hline Interface & 4 \\
\hline Informação & 3 \\
\hline Quantidade & 4 \\
\hline Qualidade & 3 \\
\hline Navegabilidade e organização & 3 \\
\hline Informação sobre a iniciativa & 4 \\
\hline $\begin{array}{l}\text { Informação sobre a prefeitura } \\
\text { e seu funcionamento }\end{array}$ & 1 \\
\hline
\end{tabular}

Conforme nossa avaliação, o website do Urbanias apresenta uma interface de boa qualidade. É, em princípio, fácil e intuitivo navegar no site e nas denúncias. O leitor pode escolher navegar diretamente pelas denúncias (através das categorias) ou clicar em suas marcações no mapa, que pode ter a escala ampliada ou diminuída de acordo com a vontade do usuário. Por outro lado, o sistema não facilita ao interessado encontrar as denúncias. Não há boas ferramentas de pesquisa disponíveis e, no geral, o sistema força o internauta a buscar as denúncias através da navegação no mapa virtual. Encontramos, por exemplo, denúncias que existem no sistema, mas que não estavam marcadas no mapa (encontradas através de link direto).
Finalmente, o Urbanias apresenta um nível razoável de informações sobre si, mas dá pouca ênfase a seu processo de funcionamento. A seção de perguntas mais frequentes (FAQ), por exemplo, denota a importância do Urbanias como mediador, mas não explica exatamente como acontece a mediação, ou seja, como a prefeitura recebe e trata as denúncias, o tempo de espera normal ou os casos em que o órgão respectivo se nega a responder ou a tratar a questão. Não há, também, informação alguma sobre a prefeitura de São Paulo e seus diferentes órgãos ou sobre maneiras de o próprio cidadão enviar suas denúncias e pedidos diretamente a estes órgãos.

\section{III) Resultados}

Para a análise, coletamos uma amostra $(\mathrm{n}=282)$ aleatória das denúncias postadas no site e, a partir disso, criamos algumas categorias de análise. Abaixo a relação da quantidade de denúncias analisadas, por categoria do site.

Tabela 2 - Distribuição das denúncias por categorias

\begin{tabular}{|l|c|}
\hline Categoria & Total de denúncias \\
\hline Acessibilidade & 20 \\
\hline Cidadania fiscal & 7 \\
\hline Segurança & 31 \\
\hline Trânsito & 39 \\
\hline Lixo e poluição & 41 \\
\hline Ruas e calçadas & 35 \\
\hline Ônibus e metrô & 38 \\
\hline Barulho & 37 \\
\hline Outros & 34 \\
\hline Total & 282 \\
\hline
\end{tabular}

O que se pode notar pela tabela é que não há uma categoria preponderante em relação às demais. Todas tendem a ter médias semelhantes de denúncias, à exceção da categoria Cidadania fiscal. Atribuímos a baixa quantidade de denúncias nessa categoria à especificidade do tema tratado, que se refere quase exclusivamente ao programa "Nota Fiscal Paulista". ${ }^{25}$

Vale ressaltar que, na amostra analisada, 127 denúncias foram feitas em 2010 e 154 foram realizadas em 2011. Esses números servem para indicar que o site continua ativo e com um número significativo de denúncias que continuam a ser postadas.

Realizamos também uma análise referente ao status da denúncia feita. Esta análise teve como obje-

24. Ver Janssen e Kies (2005) para análise de mais papéis de uma moderação ativa.

25. Programa do governo de São Paulo que permite a colocação do CPF dos consumidores nas notas fiscais para posterior ressarcimento de parte do imposto pago. 
tivo averiguar o destino das reclamações feitas no site, ou seja, se elas eram efetivamente resolvidas.

A Tabela 3 nos mostra que a maior parte das denúncias foi enviada aos órgãos responsáveis, mas não obteve resposta. É preciso notar, no entanto, que uma quantidade bastante significativa das reclamações $(24,35 \%)$ foi considerada resolvida, enquanto $22,34 \%$ das denúncias obtiveram respostas dos órgãos. Ou seja, quase 50\% das denúncias lograram um posicionamento do poder público, seja através de uma resposta apenas, seja através da efetiva resolução do problema. como pode ser visto no Gráfico 1.

Vale ressaltar aqui que consideramos como resolvidas três tipos de denúncias: aquelas cujo cidadão informava a sua resolução, aquelas cujo órgão responsável afirmava estarem resolvidas e aquelas que o próprio site marcava como resolvidas. Essa sobreposição foi necessária devido à falta de clareza do site em relação ao status das denúncias. Como a grande maioria das postagens não obtém nenhum status por parte do site, foi necessário recorrer aos comentários - seja dos órgãos, seja dos cidadãos - para averiguar como eles classificavam o status da denúncia.

Esses dados se mostram contraditórios em relação àqueles fornecidos por Balego (2011) em entrevista por nós realizada. Segundo ele, 40\% das denúncias poderiam ser consideradas resolvidas, enquanto $70 \%$ teriam respostas dos órgãos contatados. Os resultados da análise da nossa amostra, no entanto, mostram que $24 \%$ das denúncias foram resolvidas e apenas pouco mais de $22 \%$ das denúncias obtiveram respostas dos órgãos.

Um problema frequente em ambientes de participação é que, muitas vezes, eles acabam sendo domi-

Tabela 3 - Status das denúncias

\begin{tabular}{|c|c|c|c|c|c|c|c|}
\hline $\begin{array}{c}\text { Status da denúncia } \\
\text { VS. } \\
\text { Categoria }\end{array}$ & $\begin{array}{l}\text { Denúncia } \\
\text { enviada ao } \\
\text { órgão }\end{array}$ & $\begin{array}{l}\text { Órgão } \\
\text { respondeu }\end{array}$ & $\begin{array}{c}\text { Solicita mais } \\
\text { esclarecimento ao } \\
\text { cidadão }\end{array}$ & Sem status & $\begin{array}{l}\text { Órgão se } \\
\text { recusou a } \\
\text { responder }\end{array}$ & Resolvido & $\begin{array}{l}\text { Total de } \\
\text { denúncias }\end{array}$ \\
\hline Acessibilidade & 5 & 5 & 1 & 4 & 0 & 5 & 20 \\
\hline Cidadania fiscal & 3 & 0 & 0 & 1 & 0 & 3 & 7 \\
\hline Segurança & 9 & 5 & 0 & 10 & 4 & 3 & 31 \\
\hline Trânsito & 10 & 19 & 1 & 1 & 0 & 7 & 39 \\
\hline Lixo e poluição & 18 & 4 & 0 & 3 & 0 & 14 & 41 \\
\hline Ruas e calçadas & 19 & 5 & 0 & 3 & 0 & 8 & 35 \\
\hline Ônibus e metrô & 11 & 13 & 1 & 3 & 0 & 10 & 38 \\
\hline Barulho & 10 & 7 & 1 & 11 & 0 & 8 & 37 \\
\hline Outros & 14 & 5 & 0 & 5 & 0 & 10 & 34 \\
\hline Total & $99(35,1 \%)$ & $63(22,34 \%)$ & $4 \quad(1,41 \%)$ & $41(14,53 \%)$ & $4 \quad(1,41 \%)$ & $68(24,35 \%)$ & 282 \\
\hline
\end{tabular}

\section{Gráfico 1}

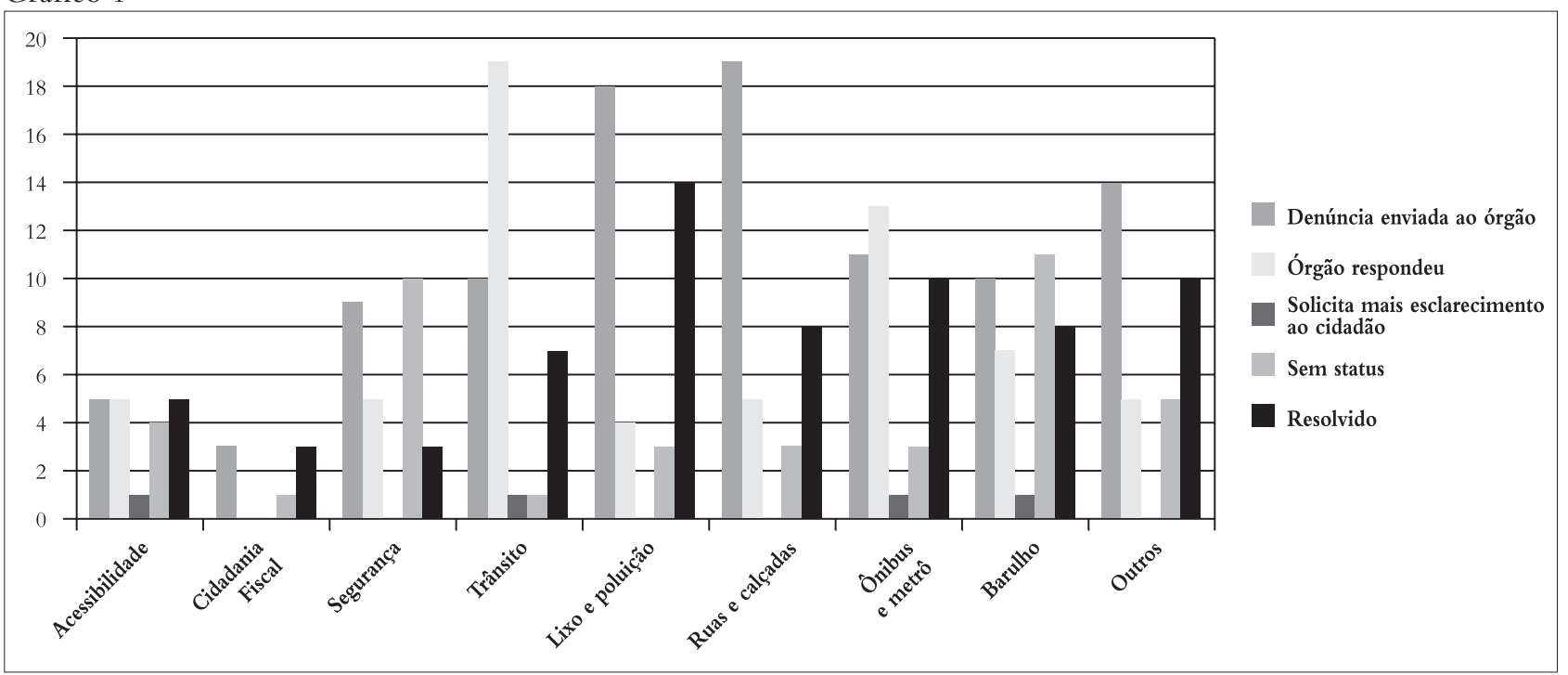


nados por poucos atores muito ativos (Davis, 2005). Se, por um lado, a participação mais ativa de determinados atores é compreensível - já que os níveis de participação e engajamento não são homogêneos entre os cidadãos (Gomes, 2011) -, por outro lado, a excessiva concentração nesses processos pode significar a diminuição do número de atores envolvidos, bem como das possibilidades de interlocução entre atores diversos (Janssen; Kies, 2005).

No Urbanias, nossa análise demonstrou que 162 usuários diferentes foram responsáveis pelas 282 denúncias analisadas. Destes, a grande maioria (132) fez apenas uma denúncia, enquanto apenas oito cidadãos fizeram mais que cinco reclamações cada um. Vale ressaltar, no entanto, que esses oito cidadãos mais ativos foram responsáveis por 92 denúncias, ou seja, mais de $32 \%$ das denúncias foram realizadas apenas por eles, o que tende a indicar uma concentração excessiva da participação de alguns atores.

Tabela 4 - Denúncias por usuários

\begin{tabular}{|c|c|c|}
\hline $\begin{array}{c}\text { Denúncias por } \\
\text { usuários }\end{array}$ & $\begin{array}{c}\text { Número de } \\
\text { usuários }\end{array}$ & $\begin{array}{c}\text { Número total de } \\
\text { denúncias }\end{array}$ \\
\hline 1 & 132 & 132 \\
\hline 2 & 17 & 34 \\
\hline 3 & 4 & 12 \\
\hline 4 & 3 & 12 \\
\hline 5 ou mais & 8 & 92 \\
\hline
\end{tabular}

Gráfico 2

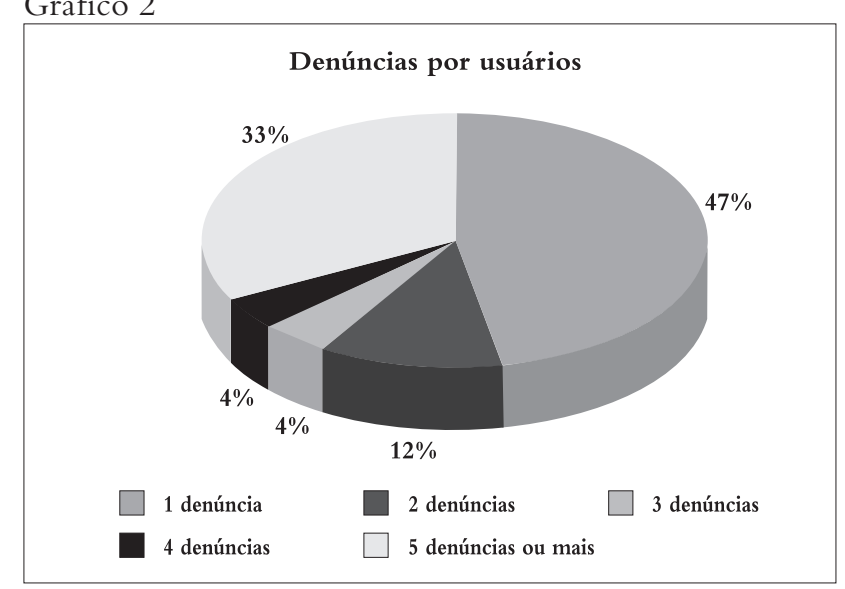

Finalmente, consideramos que seria pertinente que as denúncias apresentassem alguma evidência ou prova de sua existência, o que poderia ser realizado em vários casos com a exibição de fotos ou vídeos. Em nossa análise, observamos que apenas 15,59\% das reclamações contêm algum desses dois elementos como forma de comprovar suas denúncias. Ainda que consideremos que algumas reclamações são dificeis de provar através de imagens - como aquelas relativas a barulho e poluição, por exemplo - esse número nos parece bastante baixo.

Tabela 5 - Denúncias com fotos e vídeos

\begin{tabular}{|c|c|c|}
\hline Total das denúncias analisadas & 282 & $100 \%$ \\
\hline Denúncias com fotos & 41 & $14,53 \%$ \\
\hline Denúncias com vídeos & 3 & $1,06 \%$ \\
\hline
\end{tabular}

Como acima descrito, o sistema se provou incapaz de demonstrar se uma denúncia havia sido resolvida ou não. Foi preciso verificar os comentários. Optamos, então, por verificar todos os comentários realizados nas 282 denúncias analisadas inicialmente. O objetivo era descobrir se houve algum potencial de diálogo nas denúncias do Urbanias e, principalmente, quais eram os responsáveis por tais comentários, assim como sua distribuição. A relação entre número de denúncias e o número de comentários nos dá uma média de quantos comentários são feitos por cada reclamação postada.

Tabela 6 - Denúncias e comentários por categorias

\begin{tabular}{|l|c|c|c|}
\hline Categoria & $\begin{array}{c}\text { Total de } \\
\text { denúncias }\end{array}$ & $\begin{array}{c}\text { Total de } \\
\text { comentários }\end{array}$ & $\begin{array}{c}\text { Média } \\
\text { comentários } \\
\text { por denúncia }\end{array}$ \\
\hline Acessibilidade & 20 & 40 & 2 \\
\hline Cidadania fiscal & 7 & 14 & 2 \\
\hline Segurança & 31 & 75 & 2,4 \\
\hline Trânsito & 39 & 120 & 3,1 \\
\hline Lixo e poluição & 41 & 96 & 2,3 \\
\hline Ruas e calçadas & 35 & 88 & 2,5 \\
\hline Ônibus e metrô & 38 & 93 & 2,4 \\
\hline Barulho & 37 & 88 & 2,4 \\
\hline Outros & 34 & 88 & 2,6 \\
\hline TOTAL & 282 & 702 & 2,5 \\
\hline
\end{tabular}

A análise demonstrou que, assim como no caso das denúncias, não há uma categoria discrepante em relação às outras no que se refere a comentários. A média é relativamente muito próxima entre as categorias. A análise qualitativa dos comentários e essa média nos dão fortes evidências de que o Urbanias não é utilizado para discussões sobre os problemas da cidade ou questões mais amplas de cidadania ou mesmo para quaisquer formas de mobilização ou engajamento. No geral, a maior parte dos comentários é apenas para apresentar, respaldar ou responder a uma denúncia.

Por último, consideramos pertinente avaliar a origem do comentário, realizando sua divisão pelo tipo de autor: cidadão, Urbanias ou órgão público acionado. 
Gráfico 3 - Distribuição de comentários

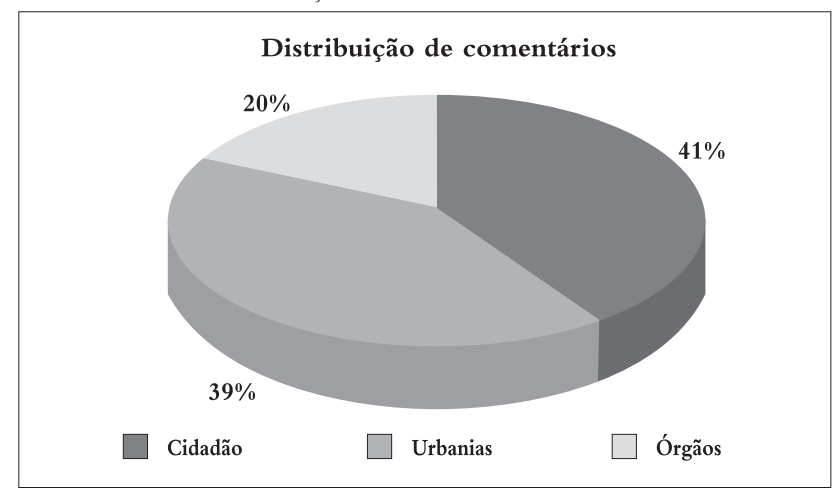

A análise desses dados revela que predominaram os comentários dos cidadãos, seguidos de perto pelos comentários do Urbanias. Esse padrão era de se esperar, já que o espaço de comentários é destinado ao cidadão e o site faz a mediação entre eles e os órgãos do poder público. O número menor de comentários dos órgãos também era esperado, visto que eles se manifestam em apenas algumas das denúncias postadas; acreditamos, no entanto, que esse percentual de $20 \%$ do total dos comentários já constitui um número bastante significativo.

\section{Incrementos democráticos}

Então, ao fim é preciso questionar: o Urbanias apresenta efetivamente algum ganho democrático? Para responder, vamos considerar os sete valores indicados por Macintosh e Whyte (2008). Como acima demonstrado, o Urbanias tem um foco quase exclusivo na apresentação e na resolução das denúncias, num processo em que cabe ao cidadão apenas indicar os problemas e, se desejar, acompanhar sua resolução ou não. Tudo indica que engajamento e deliberação não estão entre os bens incrementados. Há poucos comentários, não houve qualquer sinal de mobilização e o conteúdo demonstra apenas a utilização do site como um serviço público. A análise dos autores das denúncias e dos comentários também não apresenta quaisquer ganhos efetivos de igualdade ou pluralidade (há inclusive concentração excessiva de denúncias para poucos usuários).

Um argumento simples seria que o Urbanias é pouco democrático até porque ele se assemelha a um projeto de e-governo. Dessa maneira, ele estaria mais ligado à eficiência e à entrega de serviços públicos. Todavia, essa análise parece equivocada, porque o Urbanias é, sim, capaz de incrementar bens democráticos. Primeiramente, o Urbanias torna o processo mais transparente. Por exemplo, um serviço digital muito similar é oferecido pela prefeitura de São Paulo: o Serviço de Atendimento ao Cidadão (SAC). ${ }^{26}$ Seu sistema permite o cadastro de pequenos serviços a serem oferecidos pela prefeitura e o usuário recebe um código de cadastro que lhe permite acompanhar o andamento de sua solicitação. Contudo, o processo utilizado no SAC é pouco transparente: não é possível verificar as solicitações de outros cidadãos, nem acompanhá-las. São mostrados apenas números gerais de pedidos recebidos por órgãos do governo.

Assim, o sistema do Urbanias, mesmo em sua simplicidade, também é capaz de aumentar o controle cognitivo por parte da sociedade. Cada cidadão interessado pode acompanhar não apenas as suas demandas, mas aquelas apresentadas por outros indivíduos. Desse modo, ele pode verificar pelo mapa se há concentração de certo tipo de denúncias em alguma área da cidade e pode examinar se algum órgão está respondendo mais que outros, procurando entender os motivos para tanto. A dificuldade de realizar pesquisas on-line é um empecilho, mas o reservatório de denúncias existentes no site permite ao cidadão, ou a qualquer organização interessada, levantar os principais problemas de uma região ou da cidade, e verificar se o poder público está agindo para sanar ou minimizar tais questões. Algo que não é possível através de sistemas disponíveis na prefeitura, como o SAC.

\section{Conclusão}

Nossa análise do Urbanias conclui que o site é excelente para a realização de denúncias, mas também evidencia que ele é eficaz exclusivamente para essa finalidade. $\mathrm{O}$ site se mostrou problemático para informar e qualificar o cidadão para se inteirar dos problemas da cidade (pela dificuldade de encontrar outras denúncias ou pela inexistência de informação). A análise demonstrou que $46 \%$ dos usuários postaram uma única denúncia e que cerca de um terço das denúncias esteve concentrada em apenas oito usuários. O baixo número de comentários também evidenciou que o Urbanias não se transformou em um espaço que discute e efetivamente se engaja por sua comunidade. Para todos os usuários, o Urbanias tem sido utilizado unicamente para a solução de problemas de pequeno porte na cidade.

Essa conclusão se assemelha à de Bayakurt (2011) a respeito do FixMyStreet. Em sua avaliação, o FMS incrementa pouco a visão do cidadão sobre suas várias funções, deveres e direitos, ou mesmo sobre possibilidades de se pensar questões maiores, isto é, questões mais estruturais da cidade. Ou, em outras palavras, 
há discussões apenas sobre questões locais, pequenas, efêmeras e negativas. Não há espaço para reflexão ou proposição; não existe a efetiva possibilidade de se considerar o planejamento urbano de modo mais amplo.

O cidadão continua sendo o cliente. A iniciativa digital apenas se mostra um intermediador diferente. Bayakurt (2011) defende, assim, que o FMS deveria mudar seu design para acomodar outras possibilidades mais democráticas, como a discussão e o engajamento dos seus integrantes, para que possa se tornar algo mais próximo de uma comunidade on-line.

Embora tal crítica possa ser facilmente aplicada ao Urbanias, consideramos que esse não é o melhor caminho a ser seguido. Acreditamos que a ideia de tarefas de Coleman e Brumler (2009) seja a resposta. Nem todas as iniciativas digitais ou mesmo presenciais serão capazes de incrementar todos os bens democráticos. Se o Urbanias é incapaz de permitir essa reflexão mais geral, talvez o Cidade Democrática ${ }^{27}$ possa ser mais indicado para essa tarefa, uma vez que seu funcionamento está mais ligado à discussão entre seus integrantes e à apresentação de propostas (Rossetto, Carreiro e Almada). Ou, ainda, não é necessariamente problemático que o Urbanias seja "apenas" capaz de aumentar o poder da cidadania em conseguir a entrega de serviços. É uma vantagem. Talvez sem a sua atuação, uma parte considerável das denúncias não seria averiguada e resolvida; ou, talvez, o tempo de espera seria ainda maior.

Finalmente, se os ganhos propiciados pelo Urbanias não estão ligados à tomada de decisão e à influência na agenda do poder público, como desejam os pesquisadores de e-participação, por outro lado, eles expressam incrementos de outros valores democráticos, a saber, transparência e controle cognitivo. Valores que poderiam não existir (ou existir em menor medida) sem a intermediação do Urbanias.

\section{Referências}

ARNSTEIN, Sherry. A Ladder of Citizen Participation. Journal of the Royal Town Planning Institute, p. 1-6, April, 1971.

ÅSTRÖM,Joachim; GRÖNLUND, Åke. In: COLEMAN, S.; SHANE, P.M. (Org.). Connecting Democracy: on-line Consultation and the Flow of Political Communication. Massachusetts: The MIT Press, 2012. p. 75-96.

AVRITZER, Leonardo. Modelos de Deliberação Democrática: uma análise do Orçamento Participativo no Brasil. In: SANTOS, Boaventura de Sousa. (Org.). Democratizar a Democracia. Rio de Janeiro: Record, 2005.

BALEGO, Rafael. Gestor do Urbanias. Entrevista por e-mail realizada em setembro de 2011.

BAYKURT, Burcu. Redefining Citizenship and Civic Engagement: political values embodied in FixMyStreet. com. Anais do AoIR - Association of Internet Research, Seattle, p. 1-18, October, 2011.

BEZERRA, Heloisa Dias; JORGE, Vladimyr Lombardo. Democracia digital no Brasil: avanços nos executivos estaduais. Anais do II Simpósio de Ciências Sociais, Goiânia, p.1-15, 2011.

BOBBIO, N. O futuro da democracia. Rio de Janeiro: Paz e Terra, 1997.

BUCY, Erick P.; GREGSON, Kimberly S. Media Participation: A Legitimizing Mechanism of Mass Democracy. New Media \& Society, v. 3, nº 3, p. 357-380, 2001. CHADWICK, Internet politics: States, citizens, and new communication technologies. Nova York/Oxford: Oxford University Press, 2006.
COLEMAN, Renita; LIEBER, Paul, MENDELSON, Andrew L.; and KURPIUS, David D. Public life and the internet: if you build a better website, will citizens become engaged? New Media \& Society, no 10, p. 179-201, 2008.

COLEMAN, Stephen. Making parliamentary democracy visible: Speaking to, with, and for the public in the age of interactive technology. In: CHADWICK, Andrew; HOWARD, Philip N. (Org.). Routledge Handbook of Internet Politics. Londres: Routledge, 2009. p. 86-98.

COLEMAN, Stephen; COLEMAN, Stephen; BRUMLER, Jay G. The internet and democratic citizenship: theory, practice and policy. Cambridge, MA: Cambridge University Press, 2009.

COHEN, Joshua. Deliberation and democratic legitimacy. In: BOHMAN, James; William, Rehg (Orgs.). Deliberative Democracy - Essays on Reason and Politics. Cambridge, MA: Cambridge University Press, 1997.

COHEN, Joshua; FUNG, Archon. Radical Democracy. Swiss Journal of Political Science, v. 10, no 4, 2004.

DAVIS, Richard. Politics on-line: Blogs, Chatrooms and Discussion Groups in American Democracy. London / New York: Routledge, 2005.

De CINDIO, Fiorella; PERABONI, Cristian. Fostering e-Participation at the Urban Level: Outcomes from a Large Field Experiment. Proceedings of ePart '09. Linz, Austria, p. 112-124, 2009.

FERBER, Paul; FOLTZ, Franz; PUGLIESE, Rudy. The Internet and Public Participation: State Legislature Web Sites and the Many Definitions of Interactivity. Bulletin of 
Science, Technology E Society, v. 25, p. 85-93, 2005.

FMS. Site do FixMyStreet. Disponível em: <http://www. fixmystreet.com>. Acesso em: 17 nov. 2011.

FREWER, Lynn; ROWE, Gene. A Typology of Public Engagement Mechanisms. Science Technology Human Values, vol. 30, 2005.

FUNG, Archon. Receitas para esferas públicas: oito desenhos institucionais e suas consequências. In: COELHO, Vera Schattan P.; NOBRE, Marcos. Participação e deliberação: teoria democrática e experiências institucionais no Brasil contemporâneo. São Paulo: Editora 34, 2004.

GOMES, Wilson. A democracia digital e o problema da participação civil na decisão política. Revista Fronteiras estudos midiáticos, v. 7, nº 3, p. 214-222, set./dez. 2005a.

GOMES, Wilson. Internet e participação política em sociedades democráticas. Revista da Famecos, Porto Alegre, v. 27 , p. $58-78,2005$ b.

GOMES, Wilson. Democracia Digital: que democracia? Trabalho apresentado ao Grupo de Trabalho Internet e Política. II Congresso da Compolítica, Belo Horizonte, 2007. GOMES, Wilson. Participação Política on-line: questões e hipóteses de trabalho. In: MAIA, R. C. M.; GOMES, W.; MARQUES, F. P. J. A. (Org.). Internet e participação política no Brasil. Porto Alegre: Sulina, 2011. p. 19-45.

GRÖNLUND; Âke. ICT Is Not Participation Is Not Democracy - eParticipation Development Models Revisited. First International Conference, e Part 2009, Linz, Áustria, September, 1-3, 2009.

HABERMAS, Jürgen. Direito e democracia: entre facticidade e validade, v. 2. Rio de Janeiro: Tempo Brasileiro, 1997.

HELD, David. Modelos de Democracia. Belo Horizonte: Paideia, 1987.

JANSSEN, Davy; KIES, Raphael. On-line Forums and Deliberative Democracy. Acta Politica, no 40, p. 317-335, 2005.

KARINI, P. Metodologia de análise. Parte do material de qualificação apresentado ao Programa de PósGraduação em Comunicação e Cultura Contemporâneas. Universidade Federal da Bahia, Salvador, 2011.

KING, Stephen F.; BROWN, Paul. FixMyStreet or Else: Using the Internet to Voice Local Public Service Concerns. Anais do Icegov2007, Macao, dezembro de 2007. KOLSAKER, A., LEE-KELLEY, L.: Citizens' attitudes towards e-government and e-governance: a UK study. International Journal of Public Sector Management, v. 21, $\mathrm{n}^{\circ} 7$, p. 723-738, 2008.

MACINTOSH, Ann; COLEMAN; Stephen; SCHNEEBERGER, Agnes. eParticipation: The Research Gaps. First International Conference, ePart 2009, Linz, Austria, September, 1-3, 2009.

MACINTOSH, A.; WHYTE, A. Towards an evaluation framework for eParticipation. Transforming Government: People, Process and Policy, v. 2, n 1, p. 16-30, 2008.

MACPHERSON, C.B. A democracia liberal: origens e evolução. Rio de Janeiro: Jorge Zahar, 1978.
MAIA, Rousiley Celi Moreira. Redes cívicas e internet: efeitos democráticos do associativismo. Logos (Rio de Janeiro), v. 14, p. 43-62, 2007.

MARQUES, Francisco Paulo Jamil Almeida. Participação política e internet: meios e oportunidades digitais de participação civil na democracia contemporânea, com um estudo do caso do estado brasileiro. Tese (Doutorado em Comunicação Social) - Programa de Pós-Graduação em Comunicação e Cultura Contemporâneas, Universidade Federal da Bahia, Salvador, 2008.

MARQUES, F. P. J. A. . "Muro baixo, o povo pula": iniciativas institucionais de participação digital e seus desafios fundamentais. Opinião Pública (Unicamp), v. 16, p. 117-142, 2010.

MEIJER, A.; BURGER, N.; EBBERS, W. Citizens4Citizens: Mapping Participatory Practices on the Internet. Electronic Journal of e-Government, v. 7, $\mathrm{n}^{\mathrm{o}}$ 1, p. 99-112, 2009.

MUNHOZ, F. A. Dinamismos tecnossociais: sobre redes, colaboração e viruss. Dissertação (Mestrado em Comunicação Social) - Programa de Pós-graduação em Ciências da Comunicação, Escola de Comunicação e Artes (ECA) da Universidade de São Paulo, São Paulo, 2010.

PATEMAN, Carole. Participação e teoria democrática. Rio de Janeiro: Paz e Terra, 1992.

PANOPOULOU, E.; TAMBOURIS, E.; ZOTOU, M.; TARABANIS, K. Evaluating eParticipation Sophistication of Regional Authorities Websites: The Case of Greece and Spain. First International Conference ePart 2009, Linz, Austria, September, 1-3, 2009.

ROSSETTO, G. P. N.; CARREIRO, R. Democracia digital e sociedade civil: uma perspectiva do estado atual no Brasil. Comunicação e Sociedade, v.. 34, n 57, 2012.

ROSsetTO, G. P. N.; CARREIRO, R.; ALMADA, M. P. Democracia digital e participação: um estudo sobre iniciativas civis no Brasil. Lumina, v.. 5, nº 2, 2011.

SMITH, E.; MACINTOSH, A. Existing e-participation practices with relevance to Web.dep. WP2. Edinburgh: International Teledemocracy Centre, Napier University, 2007.

SÆBØ, Øystein et al. eParticipation: Designing and Managing Political Discussion Forums. Social Science Computer Review, n 28, v. 4, p. 403-426, 2010.

SALTER, Lee. Structure and Forms of Use. A contribution to understanding the 'effects' of the Internet on deliberative democracy. Information, Communication $\mathcal{E}$ Society, v. 7, nº 2, p. 185-206, 2004.

SAMPAIO, Rafael Cardoso. Participação política e os potenciais democráticos da internet. Debates, Porto Alegre, v. 4, no 1, p. 29-53, jan./jun., 2010.

SAMPAIO, R. C. Instituições participativas on-line: um estudo de caso do Orçamento Participativo Digital. Politica Hoje (UFPE,. Impresso), v. 20, p. 467-512, 2011.

SANFORD, Clive; ROSE, Jeremy. Characterizing eParticipation. International Journal of Information 
Management, $\mathrm{n}^{\mathrm{o}}$ 27, p. 406-421, 2007.

SMITH, Graham. Democratic Innovations: Designing Institutions for Citizen Participation. Cambridge, MA: Cambridge University Press, 2009.

URBANIAS. Site do Urbanias. Disponível em: <http:// www.urbanias.com.br>. Acesso em: 20 nov. 2011.

WILHELM, Anthony. A democracia dividida. In:
EISENBERG, J.; CEPIK, M. (Org.). Internet e Política. Teoria e pratica da democracia eletrônica. Belo Horizonte: Humanitas, 2001.

WRIGHT, Scott; STREET, John. Democracy, deliberation and design: the case of on-line discussion forums. New Media \& Society, Londres, v. 9, p. 849-869, 2007.

\title{
Report now: an analysis of e-participation in Urbanias website
}

\begin{abstract}
This article proposes an analysis of Urbanias' digital civic initiative, a website used for sending complaints on São Paulo City local problems. To this end, a complex model of evaluating e-participation was set up which considered: a) who participates; b) how they do it; and c) participation results. Interviews with managers, an evaluation of the website technical quality and a qualitative assessment of complaints $(n=282)$ and comments made; were conducted. At the end, we concluded that Urbanias has restricted potential for engagement and deliberation, but can effectively increase the transparency and population control in relation to São Paulo City government.
\end{abstract}

Key words: e-participation, digital democracy, Urbanias.

\section{Denuncia ahora: un análisis de la e-participación en el sitio web Urbanias}

\section{Resumen}

El artículo propone un análisis de la iniciativa digital civil Urbanias, un sitio utilizado para el envío de denuncias de problemas locales en la ciudad de San Pablo. Para tanto, creamos un modelo complejo de evaluación de e-participación, que considere a) quien participa b) como participa y; c) resultados de participación. Con ese objetivo, se realizaron entrevistas con los directores del sitio, una evaluación de la calidad técnica y una evaluación cualitativa de las denuncias ( $\mathrm{n}=282$ ) y los comentarios formulados. Total, concluimos que el Urbanias tiene poco potencial de participación y deliberación, pero efectivamente puede mejorar la transparencia y el control cognitivo de la población con relación al gobierno municipal de San Pablo.

Palabras-clave: e-participación, democracia digital, Urbanias. 